\title{
Articulações entre o Pensamento de Leibniz e Robine: A Gestalt-terapia Inspirada através da Dobra
}

\section{Joints between Leibniz and Robine's Thought: The Gestalt- therapy Inspired through the Fold}

\author{
Articulaciones entre el Pensamiento de Leibniz y Robine: La \\ terapia Gestalt Inspirada por el Pliegue
}

\author{
Hugo Elidio Rodrigues* \\ Instituto de Psicologia Gestalt em Figura Ltda, Rio de Janeiro, Rio de Janeiro, Brasil
}

\begin{abstract}
RESUMO
Este artigo visa aprofundar o conceito de "dobra", mencionado pelo livro "O Self Desdobrado", de Jean-Marie Robine, articulando este conceito às contribuições de Deleuze, através de sua obra intitulada "A Dobra - Leibniz e - Barroco". Para realizar tal articulação, será realizada uma contextualização histórica em relação às críticas leibnizianas ao pensamento cartesiano. Tomando a noção de dobra, segundo a interpretação de Deleuze sobre o trabalho leibniziano, como uma nova fundamentação paradigmática, serão apresentadas algumas possibilidades de utilização na prática clínica da abordagem gestáltica. Serão trazidas novas contribuições de Jean-Marie Robine ao conceito de Self da Gestalt-terapia. Concluindo o artigo, serão apresentadas argumentações tecendo uma plausível analogia entre o pensamento cartesiano tomado como fundamento, e algumas tendências contemporâneas da política brasileira. Reconhecendo como a base de pensamento a partir de um plano cartesiano, pode sugerir uma forma simplificada e reducionista de encarar temas complexos, sistemáticos, e como tal tendência de pensamento é encontrada presentemente em discursos de líderes políticos brasileiros.
\end{abstract}

Palavras-chave: dobra, Leibniz, Robine, Deleuze, gestalt-terapia.

\begin{abstract}
This article aims to deepen the concept of "fold", mentioned in the book "The Unfolded Self", by Jean-Marie Robine, articulating this concept to the contributions of Deleuze, through his work entitled "The Fold - Leibniz and the Baroque". In order to accomplish this articulation, a historical contextualization will be made in relation to the lebnizian critiques of Cartesian thought. Taking the notion of fold, according to Deleuze's interpretation of the leibnizian work, as a new paradigmatic foundation, some possibilities of use in clinical practice of the gestation approach will be presented. New contributions from Jean-Marie Robine will be brought to the concept of Self of Gestalt-therapy. Concluding the article, arguments will be presented that make a plausible analogy between Cartesian thought taken as a foundation, and some contemporary tendencies of Brazilian politics. Recognizing how the basis of thought from a Cartesian plan can suggest a
\end{abstract}


simplified and reductionist way of facing complex and systematic issues, and how such a trend of thought is currently found in speeches of Brazilian political leaders.

Keywords: fold, Leibniz, Robine, Deleuze, gestalt-therapy.

\section{RESUMEN}

Este artículo pretende profundizar el concepto de "pliegue", mencionado en el libro "El Self Desdoblado", de Jean-Marie Robine, articulando este concepto a las aportaciones de Deleuze, a través de su obra titulada "El pliegue - Leibniz y el Barroco". Para lograr esta articulación, se hará una contextualización histórica en relación con las críticas lebnizianas del pensamiento cartesiano. Tomando la noción de pliegue, según la interpretación de Deleuze de la obra leibniziana, como nuevo fundamento paradigmático, se presentarán algunas posibilidades de uso en la práctica clínica del enfoque gestáltico. Nuevas contribuciones de Jean-Marie Robine serán aportadas al concepto de Self de la terapia Gestalt. Concluyendo el artículo, se presentarán argumentos que hacen una analogía plausible entre el pensamiento cartesiano tomado como base, y algunas tendencias contemporáneas de la política brasileña. Reconocer cómo la base del pensamiento de un plan cartesiano puede sugerir una forma simplificada y reduccionista de enfrentar temas complejos y sistemáticos, y cómo esa tendencia de pensamiento se encuentra actualmente en los discursos de los líderes políticos brasileños.

Palabras clave: pliegue, Leibniz, Robine, Deleuze, terapia gestalt.

Do ponto de vista fenomenológico, a noção de tempo sempre foi a estrutura básica de pensamento, de orientação presentificante. Com o elemento crucial do cogito-cogitatum husserliano (Husserl, 2000), a Fenomenologia introduz a relação perceber-percepções, numa relação original de produção de conhecimento, que não pode ser reduzida a nenhum aspecto anterior. Ou seja, o mais básico elemento do conhecimento é a constatação, sempre no momento presente, de que percebemos o que percebemos das coisas (mundo fenomenológico), e não que percebemos as coisas diretamente (mundo ingênuo, natural). Assim como, em relação ao nosso modo de representar o passado mais profundamente o que acontece é que lembramos (tempo presente) lembranças. E sobre o futuro, que prevemos (tempo presente) previsões.

A Gestalt-terapia se nutre desse princípio e se vincula às críticas contra filosofias que retiram os aspectos temporais, presentificantes, contextualizantes, sistêmicos, holísticos e processuais da relação do ser humano consigo mesmo, com os outros, com o mundo e com o tempo. Tal postura se encontra desde o primeiro livro enquanto Frederick Salomon Perls (1893/1970), ainda psicanalista, criticava a construção teórica freudiana e lançava as bases da futura nova abordagem gestáltica (Perls, 2002). Ou seja, visões cartesianas mesmo que sejam visões mais propagadas, mais hegemônicas, são de qualquer forma visões reducionistas, individualistas, lineares e histórico-estatísticos, e são criticadas, pois com a ilusão de uma 
busca por objetividade, retiraram da relação do ser humano com o conhecimento um elemento fundamental: o contexto presente, o "mundo que é o seu", único horizonte de sentido diante do qual é possível o contato.

Para ampliar essa necessária postura crítica ao pensamento hegemônico cientificista, com forte contribuição do pensamento cartesiano, Jean-Marie Robine, em seu livro "O Self Desdobrado" (2006), nos dá algumas indicações sobre uma nova e importante contribuição, a partir de uma obra de Gilles Deleuze (1925/1995) interpretando o trabalho de Leibniz (1646/1716). O título desta obra é "A Dobra - Leibniz e o Barroco" (Deleuze, 2012).

Em seu livro "O Self Desdobrado", embora Robine não tenha incluído na bibliografia uma referência direta ao trabalho de Deleuze, em uma comunicação pessoal confirmou que, enquanto trabalhava sobre este livro, havia lido alguns livros de Deleuze. No livro "A Dobra - Leibniz e o Barroco", Deleuze, a partir da leitura de Leibniz, nos traz uma interessante forma de repensar a base do pensamento cartesiano a partir da crítica aos seus elementos básicos e oferecendo uma outra maneira de pensarmos.

Essa ligação entre "O Self Desdobrado" de Robine e o "A Dobra Leibniz e o Barroco" de Deleuze, tornou-se possível pela forma como Robine enfatiza o conceito de dobra ao longo de todo o livro. Robine já abre seu livro com a frase: "Ce que je vis comme 'moi-même', c'est à dire 'mon self', n'est rien qu'um champ replié." Traduzido em português: "O que vivo como 'eu mesmo', ou seja, 'meu self', não é nada além de um campo com várias dobras".

Porém, do que se trata mais profundamente o conceito de dobra, aqui trazido? Qual a contribuição de Leibniz, interpretada por Deleuze, que é trazida no livro "A Dobra - Leibniz e o Barroco" e que podemos aproximar do tema trazido por Robine? Para responder, vamos efetuar inicialmente uma contextualização histórica como modo de ilustrar o que Leibniz trabalhou. Um dos temas de Leibniz é sua crítica ao pensamento cartesiano. Daí, para compreendermos Leibniz, vamos primeiramente esclarecer resumidamente o alvo de suas críticas, que foi o trabalho de René Descartes (1596/1650).

Leibniz, que praticamente compartilhou o mesmo zeitgeist de Descartes, encontrou neste uma forma de perceber o mundo que, mesmo que trouxesse uma grande precisão física, não traduzia de forma correta o que podemos observar quando percebemos o que percebemos do mundo. Por exemplo, em Descartes, e em decorrência de um dos seus principais livros (Descartes, 1989) temos o seu famoso plano cartesiano onde cada imagem pode ser analisada através das linhas que emergem da abcissa horizontal " $x$ " e da ordenada vertical " $y$ ", e se encontram em um ponto preciso " $x, y$ ". Ou seja, uma análise da realidade reduzida aos critérios métricos, 
quantitativos e posicionantes, a partir dos elementos constitutivos de "linhas" e "pontos".

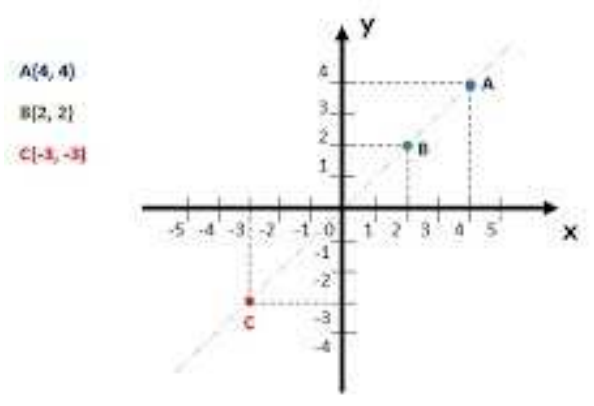

Figura 1 - Plano Cartesiano

Fonte: Blog Professor Ferreto (2018). Recuperado de:

https://blog.professorferretto.com.br/nocoes-basicas-de-planocartesiano/

Com um plano cartesiano como forma de representar o mundo, temos toda uma decorrente percepção de precisão, de objetividade, de limite, de "sim e não" (base da futura linguagem binária dos computadores, o " 0 " ou " 1 "), do que está dentro e o que está fora, de linearidade, de análise por decomposição dos pontos que formam o objeto analisado.

Filosoficamente, Descartes traz uma exaltação à racionalidade, à preponderância das ideias claras e distintas, tanto que esta racionalidade fica como responsável inclusive pela conclusão de minha própria existência, já que eu só posso ter certeza de que existo na medida em que eu penso. Daí a famosa frase que passou a história como o "Cogito Cartesiano", o "Penso, logo existo".

Remetendo-nos ao conceito de "paradigma" (do grego, "padrão, modelo que se demonstra") como abordado por Cunha (1982), entendemos como uma ideia de um campo filosófico pode influenciar ou fundamentar conceitos em outros, e como a "certeza da cientificidade" influenciou critérios éticos, estéticos e sociais da cultura dos séculos XV, XVI e XVII trazendo influências até hoje. Somente para ilustrar, é o que encontramos no campo da arte, com o movimento cultural do Classicismo. Neste movimento, percebemos como uma pintura clássica era elaborada com a clareza dos temas trazidos em planos divididos, como por exemplo, o plano divino, o céu, o nível superior em oposição ao plano terreno, imperfeito, inferior. Como modo de ilustrar, pode ser citado o quadro de Rafael na pintura "Transfiguração" de 1520.

Historicamente, temos inúmeros trabalhos que apontam para como 0 paradigma cartesiano se manteve vivo e hegemônico em nossa cultura ocidental, como por exemplo, o de Shorto "Os Ossos de 
Descartes", de 2013. Esta explanação, entretanto, foge do escopo do presente trabalho. Mas é relativamente óbvio constatar que, com a conjugação da ciência com o capital industrial, o que faz surgir a tecnologia, a proliferação das indústrias torna a ciência e o que é científico algo com uma espécie de valor moral intrínseco, como se todos pudessem acreditar que, o que é aclamado como "científico", é considerado imediatamente verdadeiro.

O cartesianismo, calcado sobre o cogito e a racionalidade decorrente, traz uma indubitável visão de que, em cada mente, há uma existência. Esse solipsismo racional fundamenta filosoficamente as bases do individualismo, onde cada pensamento pensado é um produto de uma unidade apartada de qualquer espécie de coletividade, contexto ou história. Minha existência se deve ao meu pensamento.

No cotidiano social, campo maior da atuação do nosso trabalho psicológico, podemos constatar como essa influência cartesiana, cientificista, com a precisão das linhas e pontos, ajudou a moldar os comportamentos. Na experiência clínica, mostra-se muito pertinente a suposição de que algumas frases ou ideias teriam sua origem proveniente desta fundamentação cientificista. Para ilustrar:

1) "Você deve andar na linha!"

2) "Claro que você deve ter certeza absoluta daquilo que está sentindo!"

3) "A partir de que ponto você deixou de me amar?"

4) "Vamos direto ao ponto!"

5) "A razão é superior à emoção!"

6) "Esse é o nosso lado certo. Do outro lado, está errado!"

7) "Minha cabeça, meu único guia!"

8) "Ponha-se no seu lugar!"

9) "Nasci só e morrerei só!"

10) "Esse é o meu ponto de vista!"

Sobre esta última frase, Deleuze (2012) aprofunda um pouco mais essa discussão que parece privilegiar o "ponto" através do qual algo é visto, quando na verdade, o que deveria ser privilegiado seria o que é visto e que converge para um ponto. Deleuze nos fala sobre isso: "Trata-se não de uma variação da verdade de acordo com um sujeito, mas da condição sob a qual a verdade de uma variação aparece ao sujeito." (Deleuze, 2012, p. 39-40). Uma vez que, mesmo quando olhamos para um "ponto de vista", o que vemos de fato é uma vista onde inclui um ponto. Ou seja, a visão fisicamente sempre nos trará uma curva, nunca um ponto. A noção de ponto de vista enaltece a pessoa, como se a vista fosse a partir do ponto dela, quando na realidade o que acontece é algo mais complexo, já que é a relação da vista mostrada ao ponto que vê, que torna a emersão do sentido 
possível. Ou seja, uma visão que muito se aproxima da noção gestáltica de "campo".

A noção da linha cartesiana também gera um perigo, de fazer com que os Gestalt-terapeutas entendam de forma reduzida, noções importantes como "fronteira de contato", pois pensando cartesianamente esse conceito gestáltico, erroneamente poderia ser interpretado que, de fato, há uma linha que separa organismo e ambiente. Entretanto, mesmo uma fronteira que separa organismo e ambiente, sempre se dá em um campo onde tal fronteira emerge com um sentido. Isso aponta para um possível erro em relação a como, na Gestalt-terapia, um conceito tão importante pode ser "reduzido" sem que tivéssemos cuidado para evitar tal compreensão. Pois não é possível conceber que, de fato, haja uma linha como uma "fronteira" e de um lado haja um organismo e de outro haja o ambiente. O que há é uma tridimensionalidade, que engloba, que "se curva", envolvendo a situação que pode se desdobrar em diferentes sentidos.

Outro aspecto onde o paradigma sob a linha e o ponto influencia, certamente, é sobre o pensamento dicotômico que divide uma realidade entre um sim/certo e um não/errado. A linha, mesmo que simbolicamente, induz à espacializarmos isto. Como se o mundo fosse dividido e a mente se pergunta: "Onde está aquele ponto?" E a resposta então busca em que lado da linha divisória da questão o ponto está, para então responder: "Certo, por estar do meu lado!" Ou o oposto. Uma poderosa e ilusória simplificação que, na presente realidade brasileira, encontramos formas políticas de exploração. Sob a égide desta simplificação de pensamento, podemos colocar no plano cartesiano homens de um lado vestindo a cor azul e mulheres de outro vestindo a cor rosa. E ainda, cada um, representado dividido pela abcissa horizontal " $x$ ", da parte do corpo do tórax para cima, representando a parte tida como superior e nobre; da outra parte do tórax para baixo, a parte tida como inferior e pecaminosa. Tais pensamentos, tão evidentes em nossa contemporaneidade políticasocial brasileira, não surpreendem ao produzir um contexto onde algo tão cartesiano como uma concepção de "terra plana" possa novamente emergir. Ou ainda, ao nível internacional, a volta da ideia de erguer muros para dividir povos ou nações.

Mais um outro fator importante sobre o pensamento cartesiano que precisamos trazer, especialmente pela relevância que explanaremos mais à frente. Em termos descritivos, quando olhamos para um plano cartesiano e vemos as duas linhas, a coordenada e a abcissa, elas estão postas sobre um plano, uma superfície como um quadro branco ou como uma folha branca. Inadvertidamente, podemos então supor que, no plano cartesiano, a figura que é colocada sobre o fundo branco é o tema, é o foco, é aquilo que está sendo analisado. E o fundo não interage, dada sua pretensa e não discutida 
homogeneidade, tornando o tema ali analisado algo como por sobre um fundo que não deve trazer problemas, pois a mente científica está preocupada com o objeto analisado, não com seu contexto ou fundo, que deve então, permanecer neutro.

Algo que na ciência é largamente conhecido como as "CNTP": "Condições Normais de Temperatura e Pressão". Essa mensagem implícita, como se fosse possível encontrar de fato na cotidianidade as CNTP, ou seja, uma situação neutra que me permitisse apenas focar um tema por vez, sem interferência alguma do contexto ou fundo, é algo que ao mesmo tempo em que é tão inviável (fazendo com que as experiências passassem para um outro campo de experimentação que não a realidade mundana, mas sim, a realidade artificialmente controlada dos laboratórios), é algo que também retira o que torna o sentido de alguma coisa possível: o fundo referencial, conceito tão prezado pela abordagem gestáltica. Para este momento, pedimos que seja mantido na mente do leitor o plano cartesiano como se ele estivesse desenhado em uma folha em branco, lisa, homogênea, neutra. Retomaremos à crítica desta imagem posteriormente.

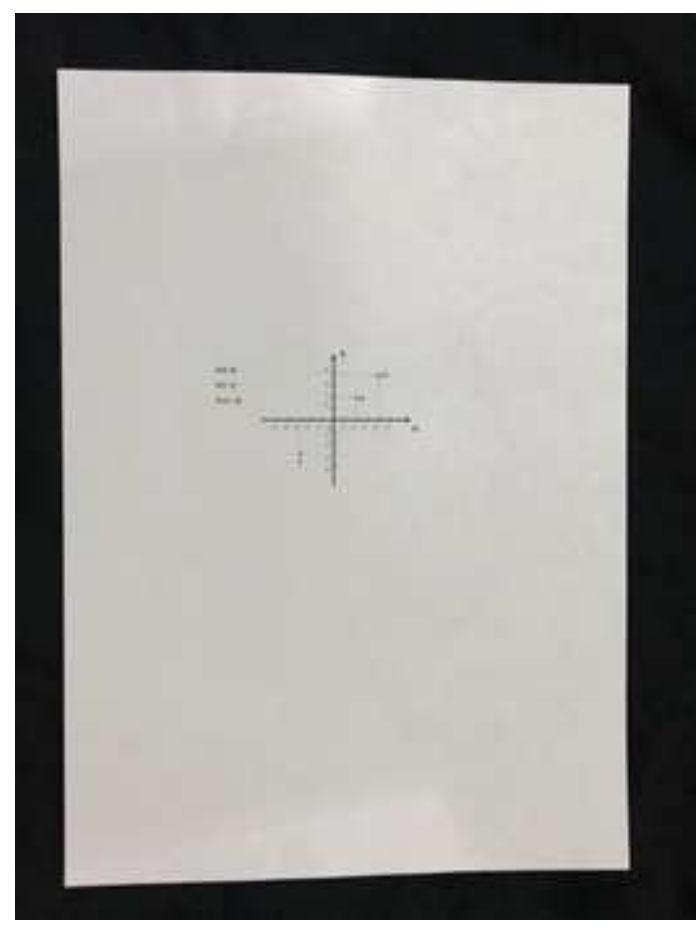

Figura 2 - Folha lisa

Fonte: O autor (2019)

Retomando, daí decorre que podemos de fato representar "cientificamente" o mundo assim, mas isso confere ao modo como percebemos o que percebemos da realidade em nossa volta e em mim? Somos seres de fato objetivos, precisos, com clareza total de 
nossos limites exatos? Nossos contextos de vida são "lisos", homogêneos, neutros? Não, mesmo que possamos tentar muito, mas não somos e nem vivemos assim.

Quando percebemos nossa realidade humana percebida, nos deparamos muito mais com incertezas, com ciclos de eventos recorrentes, com situações que vão amadurecendo, com contextos irregulares, surpreendentes, imprevisíveis, sem que percebamos a partir de qual momento exatamente, algo que era de um jeito, passa a ser de outro modo.

A partir do trabalho de Leibniz, Deleuze em seu livro já acima citado nos diz que um paradigma, cujos elementos constitutivos são representados por uma linha e por pontos, não estão em sintonia com a realidade humana. O que Leibniz então propõe? Vamos acompanhar uma proposta de percepção da realidade que, mesmo aparentemente sendo algo simples, tal simplicidade apresenta um potencial heurístico muito maior. Leibniz nos propõe que, ao invés de linhas, passemos a perceber como a realidade se apresenta em forma de curvas. Que, ao invés de pontos, pensemos em inflexões. Deleuze apresenta uma imagem de referência algo com um " $\mathrm{S}$ " para ilustrar a visão de curva, conforme apresentado em seu livro (Deleuze, 2012, p. 32). Mas como seria isso? E como isso se aproxima do pensamento gestáltico?

Pensemos: como definimos uma "curva"? A curva não é algo definível como um estímulo, como uma única informação. Assim como a sensação do "áspero", que só é sensível com um conjunto de informações, a curva igualmente é algo que não se mostra pontualmente. Mostra-se gestalticamente. É uma informação que só faz sentido vista como uma situação, uma forma que é percebida assim. E como vai se dando? Através da inflexão, ou seja, a própria mudança que torna uma linha em uma curva. Essa mudança, também não é uma construção definida com exatidão, pois é algo que vai sendo percebida e criando formas enquanto seu processo acontece. Segundo Deleuze: "A dobra ... faz aparecer a Forma, fazendo dela uma forma de expressão, Gestaltung, o elemento genético ou a linha infinita de inflexão, a curva variável única." (Deleuze, 2012, p. 66).

Simbolicamente, podemos efetuar uma analogia com a dinâmica psicológica do amadurecimento humano. A partir de qual ponto exato deixamos de ser um adolescente e nos tornamos um adulto? Não é possível definirmos a partir de qual ponto exato nós percebemos que houve uma mudança. Enquanto que o ponto e a linha nos sugerem uma cisão, uma localização exata em que um "lado da história", um "até esse ponto era assim, e a partir daqui é outra coisa", a noção da curva e inflexão nos dá a noção de gradação (outra noção tão prezada pela Gestalt-terapia), através da qual algo vai indefinidamente se dando, mudando, sem que tenhamos precisão a 
partir de onde exatamente. Ao invés de "lado da história", lidamos com o campo no sentido que a história se mostra ou se desdobra em suas várias possibilidades de mostração.

Segundo Leibniz, a realidade percebida se mostra como em dobras, curvando-se sobre si, criando em cada dobra, possíveis novos desdobramentos. Especialmente com o mundo biológico, esse paradigma da dobra se mostra muito mais preciso. O corpo biológico se mostra como desdobramentos a partir de desdobramentos, partindo de elementos simples como células, envolvidos por elementos mais complexos como membranas, até que se desenvolvem posteriormente em outros órgãos mais complexos ainda.

Voltando ao exemplo sobre a folha lisa mencionada antes, aqui podemos comparar como é lidar com as superfícies que contemplam indefinidas possibilidades, como é, por exemplo, no caso do mesmo papel, mas agora se apresentando contendo várias pequenas curvas, como obtemos quando uma folha é amassada e depois estendida. Qual a aparência deste mesmo papel agora?

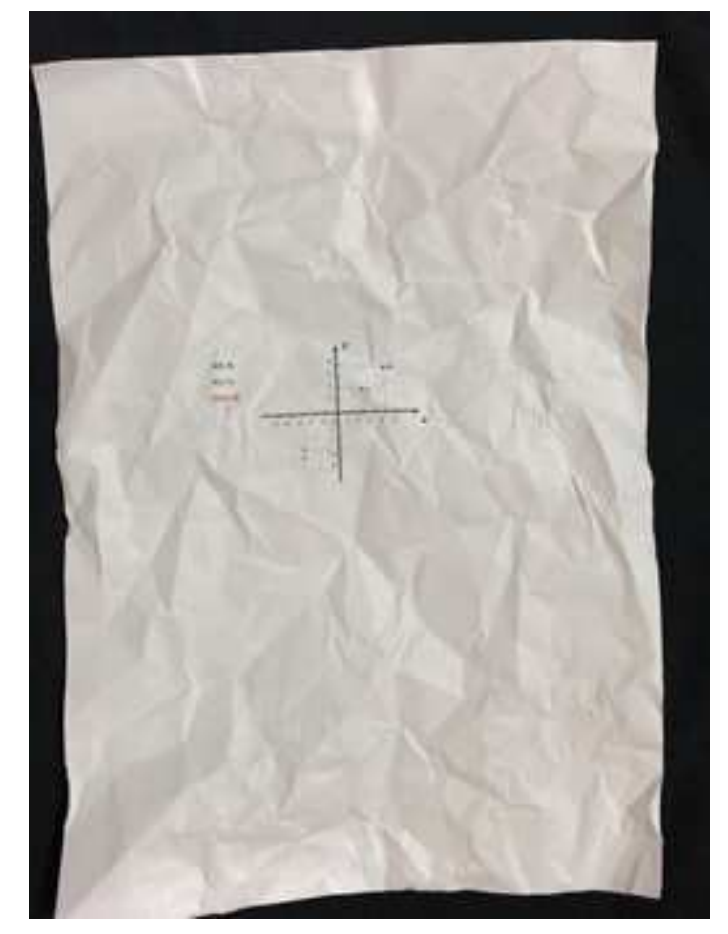

Figura 3 - Folha amassada

Fonte: O autor (2019)

O fundo apresentará muitas dobras, muitas curvas, gerando muitos campos entremeados pelos reflexos da luz e o ocultamento das sombras. Apresentará heterogeneidade, apresentará surpresa, apresentará o inesperado. Aqui cabe trazer novamente uma conexão com o universo da arte. Deleuze faz a conexão do pensamento de 
Leibniz com o estilo que encontramos na arte barroca. Estilo este onde os fundos são escuros, sem muita nitidez ou precisão, e as figuras emergem de forma não muita clara. Como exemplo, pode ser citada a obra de El Greco, em sua consagrada pintura "A Morte de Conde Augraz" de 1588.

Deleuze explora ainda um pouco mais esta capacidade de expressão de uma superfície não lisa, que pode indefinidamente ser cada vez mais dobrada e redobrada, ampliando crescentemente seus detalhes, seus campos iluminados e sombrios. É inspirador trazer essa simbologia para se pensar o processo psicoterápico. Como se a cada sessão, a pessoa em terapia pudesse se ampliar, diferenciar-se, reconhecer-se em mais profundos detalhes. Para ilustrar essa simbologia, podemos nos inspirar, indo na sequência da primeira imagem do plano cartesiano sobre a folha branca:

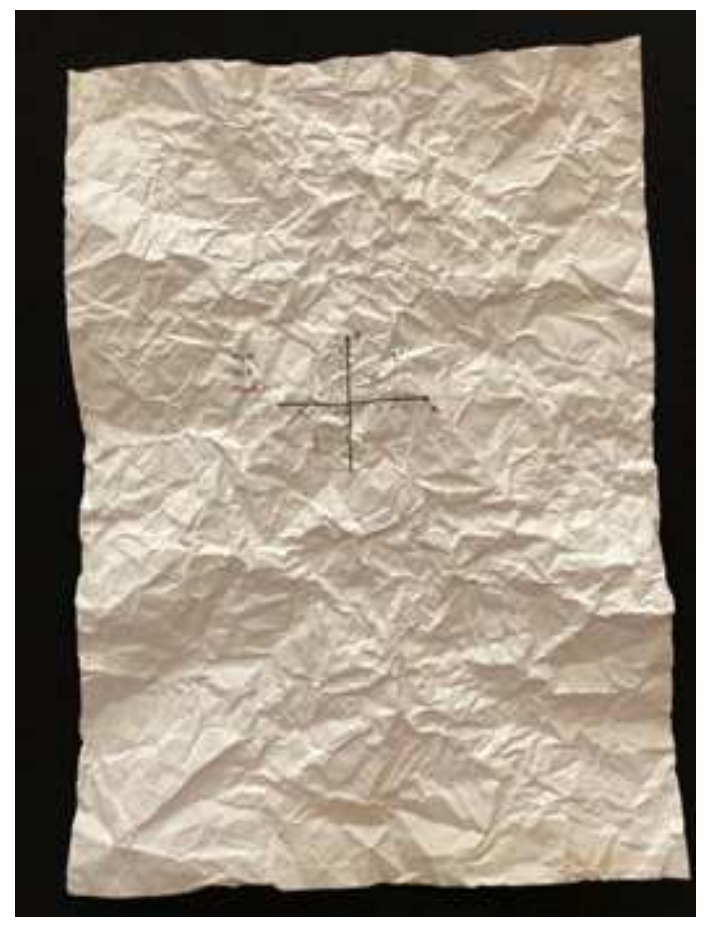

Figura 4 - Folha amassada e redobrada

Fonte: O autor (2019)

Este processo de continuidade de dobra e desdobramento, poderia ser também relacionado dinamicamente com outro conceito prezado pela Gestalt-terapia, que é o conceito lewiniano de "diferenciação", proveniente da Teoria de Campo (Lewin, 1975). Através deste conceito, Lewin nos explica sua compreensão de como o amadurecimento humano pode ser operacionalizado e representado pelo seu "método geométrico da construção". Lewin nos explica que um bebê, caso pudesse representar seu mundo através de um círculo e fosse pedido que ele dividisse esse círculo nas partes componentes 
do seu mundo, talvez ele o dividisse em apenas dois. Em um campo seria "mamãe" e em outro campo seria "não é mamãe", ou seja, todo o resto. Alguns anos depois, essa criança já dividiria o círculo em mais outras partes, incluindo mais membros da família, incluindo escola e o espaço fora de casa. Mais alguns anos depois, esse adolescente já teria uma divisão muito maior, incluindo lugares onde frequenta, amigos ou amigas mais íntimas, lugares para onde gosta de viajar, etc. Ou seja, segundo Lewin, na medida em que amadurecemos, teremos cada vez mais campos diferenciados de experiências, como se a vida fosse se abrindo em novas situações. Poeticamente, podemos fazer uma imagem da vida como um potencial enorme de se desdobrar, criando novos campos de luz e consciência que abrem dialeticamente novos campos de sombra e desconhecimento. Nunca estaremos "prontos", mas sempre em processo.

Deleuze também ressalta a inspiração artística das superfícies que se desdobram, e menciona em seu livro o trabalho de alguns artistas, como Simon Hantaï, pintor francês de origem húngara. O relevante desta informação é que esta mesma ideia da superfície irregular, foi também aparentemente captada por Robine, que utiliza esta mesma mensagem como nada mais nada menos do que a imagem de capa do seu livro, originalmente lançado pelo seu instituto na França:

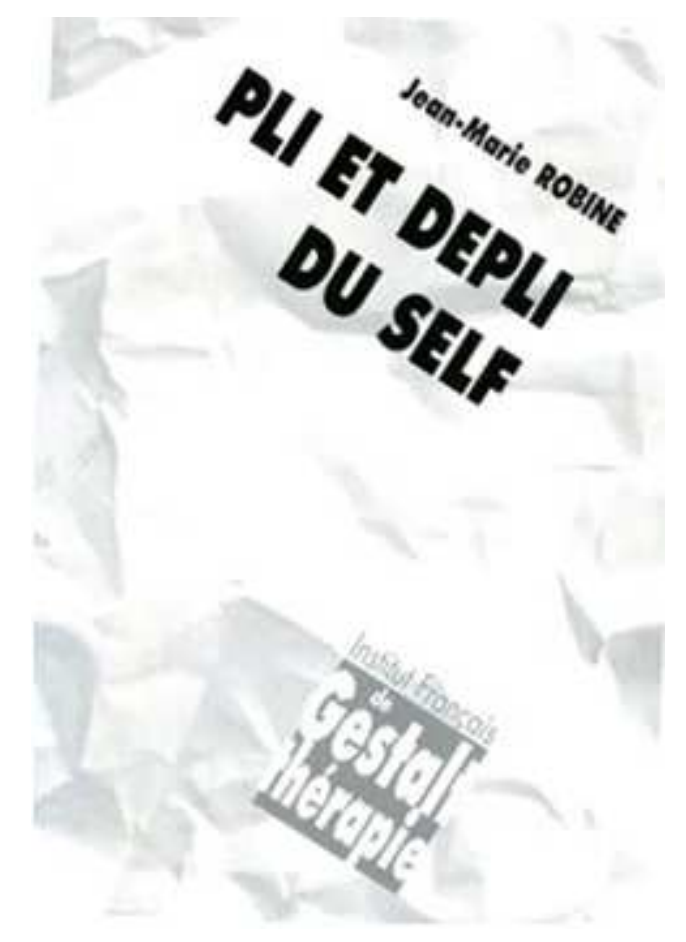

Figura 5 - Capa do livro "Pli et Depli du Self" de Robine lançado pelo Institut Français de Gestalt-thérapie Fonte: Imagem pública da capa do livro (2019) 
Como podemos compreender a importância dessa nova visão paradigmática para a Gestalt-terapia? O que pode nos trazer uma visão não linear e pontual, mas sim uma visão que se desdobra?

No livro "O Self desdobrado", já acima citado, Robine privilegia uma retomada à concepção temporal do conceito de Self da Gestaltterapia, dando também importância à concepção de campo, sendo o Self algo que se dá num campo de sentido, como um processo e não como uma ação única, como um ato de contatar, mas como "uma sequência" (Robine, 2006, p. 14). No campo, o Self se apresenta em função dos seus modos de responder. O modo Id, que surge na situação de pré-contato, aciona os modos de contatar (como o contato irá se dando, em função da necessidade do campo), ou seja, o campo acionará o modo de sonhar, de imaginar, de prever, etc. Isso, em relação àquilo que, no modo Ego, será o foco sonhado, imaginado, previsto, entre outros. É importante aqui retomar a base fenomenológica da construção da realidade, que é a relação noéticanoemática, segundo Husserl (2006). Como fechamento do processo, da síntese do que é vivido na situação pelo Self em suas funções Id e Ego, as experiências se articulam as outras anteriores, pela função Personalidade.

Mas Robine ainda considera que esta definição tem uma visão mais simplista, sendo o contato algo mais complexo e fundamentado não na noção do Self, ou ainda na relação organismo/meio, mas sim na noção de campo. Segundo Robine (2006): "O contato é dobra e redobra do self, o self é dobra e redobra do campo, em uma dança incessante." (p. 15). No original em francês, citado na tradução para o português, o tradutor conserva a frase original: "le contact est pli e repli du self; le self est pli e repli du champ." Ou seja, o uso da mesma palavra utilizada por Leibniz para expressar sua noção de dobra. Como citado na frase original em francês, a palavra "pli", ou "plica" em latim, significa dobra. Daí, a origem dos termos ex-plica, ou ex-plicita (desdobra, desdobrada), com-plica (reunir dobras) e implica (se dobra sobre). Dentro desta lógica etimológica, o título "O Self Desdobrado", poderia ser compreendido como "O Self Explicado". Em uma troca de mensagens pessoais, Robine esclareceu que sua concepção do Self pensado como dobra evoluiu mais, obviamente, já que ele é um pensador em atuação, e já percorrido mais de duas décadas em relação à edição original do seu livro. Segundo suas próprias palavras:

Today, one step further, I would like to avoid the implicit idea that there could be 'somewhere' a hidden folded self which could be unfolded when necessary to make a creative adjustment, but that self is BOTH an emergent function of the field in a creative-adjustment process, AND the organiser and 
artist of this process. (Troca de e-mail pessoal ocorrida em 26 de agosto de 2019).

Em livre tradução:

Hoje, um passo à frente, gostaria de evitar a ideia implícita de que poderia haver 'em algum lugar' um self oculto dobrado que poderia ser desdobrado quando necessário para fazer um ajuste criativo, mas que o self é AMBOS uma função emergente do campo num processo de ajustamento criativo, E O organizador e o artista deste processo. (Troca de e-mail pessoal ocorrida em 26 de agosto de 2019).

Em um livro mais recente, Robine nos fala do Self como "deslocalizado" e temporalizado (Robine, 2018, p. 219).

E, em consonância com a mensagem do Robine, temos o trabalho de Távora, alertando que o pensamento em curvas e inflexões não pode nunca se confundir com alguma tentativa de representação geométrica do self (Távora, 2018). Porque Self não é uma coisa, não é algo localizável, e sim, um processo que incessantemente se dobra e se desdobra.

Ou seja, o desdobramento e sua simbolização precisam ser pensados temporalmente, e não espacialmente (Távora, 2018). Por isso, Robine também nos alerta como não podemos tomar o que o Self vive e reduzi-lo artificialmente a um suposto produto do que é vivido. Ou seja, temporalmente, o que fenomenologicamente se descreve é diferenciação. Não individuação. "Individuação" é uma interpretação, um suposto e ilusório "produto" proveniente do processo de se diferenciar. Fenomenologicamente, o que descrevemos é o processo aqui-e-agora que vai se dando. Não o produto dele, pertencente ao passado. Logo, o processo de diferenciação não pode ser confundido com o produto disto, a individuação (Robine, 2018). Outro aspecto importante é que, descritivamente, não podemos falar de "interrupção de contato", mas somente de interrupção de figuras de contato. Pois, sendo processo, um contato não é interrompido e "ponto". Descritivamente, o que acontece é que ele é mudado enquanto objeto (algo estava sendo percebido e a atenção passa para outro foco) ou modalidade (um cliente em terapia que estava se emocionando e passa a contar uma história racional sobre como ele pensa que sente as coisas).

Távora também inclui a questão da dobra:

O aspecto mais significativo desses processos concerne à possibilidade de uma evolução por meio de variação. Nesse processo, ao desempenhar seu comportamento, o sistema observa, à medida que as consequências de suas atividades se 
dobram de volta sobre si mesmas, o que nos remete ao funcionamento do self no 'modo médio', conforme descrito por PHG. (Távora, 2018, p. 51).

Pensando em dobras e redobras, Robine sugere uma imagem para representar simbolicamente o processo que cria e ao mesmo tempo é criado (o modo médio). Para ilustrar, pode ser citada como exemplo a figura do pintor holandês Maurits C. Escher (1989/1972), o "Drawing Hands" de 1948. Dinamicamente, este processo não pode ser pensado em termos de unidade, um indivíduo em um processo somente seu de amadurecimento ou de se perceber isolado ao longo deste processo. Podemos pensar em um campo que se desdobra, uma situação onde sistemicamente todos os elementos interagem de modo que nenhum pode ser compreendido isoladamente, por si.

Incluindo aqui e desdobrando outro campo de atuação psicoterapêutica, tal forma de pensar é claramente constatada nos workshops que se utilizam da "Constelação Familiar", trabalho psicoterapêutico baseado no trabalho de Bert Hellinger (Hellinger, 2007). Em um trabalho terapêutico nesta abordagem, o foco do trabalho não é idiográfico, mas descritivo sobre a forma como as pessoas, chamadas como representantes do sistema familiar focado, são posicionadas pela pessoa que se propõe "constelar", ou seja, que se propõe a trabalhar suas questões. É significativa a aproximação entre a constelação familiar e a simbologia aqui representada, do papel que pode ser amassado e depois desdobrado, e ainda voltar a ser amassado mais ainda e ser novamente desdobrado, e mostrar-se com curvas ainda mais sutis, mais surpreendentes.

Retomando ao tema mais palpável dos comportamentos e das expressões faladas que indicam formas de pensar, conforme as frases sob influência do pensamento cartesiano citadas há algumas páginas atrás, podemos questionar como o paradigma leibniziano poderia ser mais próximo ao pensamento gestáltico somente experimentando as mesmas frases escritas anteriormente, porém agora sob este novo paradigma. Como ficariam? Como seria pensar nelas em termos de curvas e inflexões? Para ilustrar:

1) "Vá percebendo por onde você anda, na medida em que você for andando!"

2) "Claro que o que você sente pode ir se desdobrando em formas diferentes!"

3) "Nosso amor foi se desdobrando de uma forma tal que, quando nos demos conta, estávamos vivendo um término!"

4) "Vamos nos aproximando e checando se estamos falando do que é essencial?"

5) "Razão e emoção se desdobram numa unidade perceptiva!" 
6) "Posso supor que estou certo, mas podem surgir desdobramentos que me indicam o contrário!"

7) "Sou guiado pela situação por mim vivida."

8) "Vou experimentando em qual situação me sinto melhor."

9) "Nasci e morrerei em um contexto familiar."

10) "Essa é a forma como eu estou vendo o que está se mostrando para mim até agora."

Frases cujo sentido são mais "gestálticas".

Concluindo o presente artigo, três objetivos foram propostos. 0 primeiro objetivo foi compartilhar a visão da profundidade da noção de dobra em Leibniz e sua pertinência para a Gestalt-terapia. No livro de Robine original em francês (Robine, 1998), não é feito tal aprofundamento e, no livro traduzido para o português, sobre o conceito de dobra, há tão somente uma única pobre nota de rodapé logo na primeira página (onde poderia ser possivelmente uma "dedicatória") explicando o significado do conceito "champ replié" e "champ deplié". Segundo a nota: "Robine utiliza frequentemente nesta obra os termos champ replié e champ deplié (campos com várias dobras/campo desdobrado), termos de difícil tradução em português, mas que têm o sentido de deixar vincos, marcas, como em uma roupa dobrada." (Robine, 2018).

O segundo objetivo foi compartilhar uma pequena parte da atualização do pensamento de Robine.

O terceiro objetivo foi apresentar informações que podem ajudar o psicólogo que trabalha com uma visão sistêmica, fenomenológica ou holística, de como compreender a base do pensamento cartesiano, individualista, reducionista e linear-causal. Esta base vem se tornando cada vez mais evidente, fundamentando ações de líderes políticos que manifestam suas opiniões onde claramente toda a questão social-histórica (ou seja, o contexto) é ignorado.

Um contemporâneo exemplo real concreto: um líder político que expressa não ter sido ele quem teve navios negreiros, que não foi ele quem comprou nenhum escravo da África e nem escravizou ninguém. Desta forma, como não foi ele quem fez isso, logo, não tem dívida nenhuma sobre tal assunto. Traduzindo este pensamento em termos cartesianos: o ponto que eu sou neste plano, lida apenas com as questões que estão relacionadas com o ponto que eu sou. Só lido unicamente com o que está acontecendo agora, de acordo com o que interessa.

Porém, traduzindo esse mesmo pensamento pelo polo oposto, em termos leibnizianos: como um líder, não sou eu apenas que vejo o que eu quero ver, mas também sou visto. Ao ser visto, o que faço atinge quem me vê, logo, tenho uma responsabilidade pelo exemplo das minhas ações em como isso estimula positivamente ou negativamente quem me vê. Além de como sou visto, estou 
representando aqui uma liderança, que se desdobra para além do indivíduo que eu sou, pois abrange aquilo que o cargo demanda de $\mathrm{mim}$. Este cargo tem uma história, um presente e um futuro. Assim sendo, minhas ações com representante no momento deste cargo, precisa considerar este passado, presente e futuro, pensando em outros representantes que, no mesmo papel, podem ter feito algo que não deveria ter sido feito, ou fazer algo que deveria ter sido feito e não o foi.

Seria difícil de imaginar o Papa João Paulo II dizendo: "Não fui eu quem julgou Galileu de heresia. Não devo nada a ele!" Ao mesmo tempo em que é tão louvável este mesmo Papa, considerando seu papel de representante da liderança católica no mundo, assumir os erros da história e pedir desculpas pelo tratamento dado à Galileu, exaltando-o, de acordo com a relevância que este pensador merece.

\section{Referências}

Cunha, A. G. (1982). Dicionário Etimológico Nova Fronteira da Língua Portuguesa. Rio de Janeiro, RJ: Nova Fronteira.

Deleuze, G. (2012). A Dobra - Leibniz e o Barroco. Campinas, SP: Papirus.

Descartes, R. (1989). Discurso do Método. São Paulo, SP: Ática.

Hellinger, B. (2007). Constelações familiares: o reconhecimento das ordens do amor. São Paulo, SP: Cultrix.

Husserl, E. (2000). A Ideia da Fenomenologia. Lisboa: Edições 70.

Husserl, E. (2006). Ideias para uma Fenomenologia Pura e para uma Filosofia Fenomenológica. Aparecida: Ideias \& Letras.

Leibniz, G. W. (1974). Os Princípios da Filosofia Ditos a Monadologia. São Paulo, SP: Abril Cultural.

Lewin, K. (1975). Teoria Dinâmica da Personalidade. São Paulo, SP: Cultrix.

Perls, F. (2002). Ego, Fome e Agressão - Uma revisão da teoria e do método de Freud. São Paulo, SP: Summus.

Robine, J. (1998). Gestalt-thérapie - La Construction du soi. Paris: Editions L'Harmattan.

Robine, J. (2006). O Self Desdobrado - Perspectiva de campo em Gestalt-terapia. São Paulo, SP: Summus.

Robine, J. (2018). Self - Uma Polifonia de Gestalt-terapeutas contemporâneos. São Paulo, SP: Escuta.

Shorto, R. (2013). Os Ossos de Descartes. Rio de Janeiro, RJ: Objetiva.

Távora, C. B. (2018). "Because the world is round, it turns me on": self como interface forma-conteúdo na prática clínica contemporânea. In J. Robine (Ed.), Self - Uma polifonia de 
Gestalt-terapeutas contemporâneos (pp. 31-56). São Paulo, SP: Escuta.

\section{Endereço para correspondência Hugo Elidio Rodrigues}

Rua Barão de Mesquita, 380 apto 401, Vila Isabel, CEP 20540-146, Rio de Janeiro RJ, Brasil

Endereço eletrônico: psicologiaclinica@yahoo.com

Recebido em: 13/10/2019

Reformulado em: 05/01/2020

Aceito em: 08/01/2020

\section{Notas}

* Psicólogo pela UERJ (1994), Mestre em Psicologia Social (UERJ- 2005), Professor convidado pela UERJ (entre 2006 e 2008), diretor do Instituto de Psicologia Gestalt em Figura.

Este artigo de revista Estudos e Pesquisas em Psicologia é licenciado sob uma Licença Creative Commons Atribuição-Não Comercial 3.0 Não Adaptada. 